Check for updates

Cite this: RSC Adv., 2018, 8, 8118

Received 18th December 2017 Accepted 5th February 2018

DOI: 10.1039/c7ra13423a

rsc.li/rsc-advances

\title{
Electrolytic extraction of dysprosium and thermodynamic evaluation of Cu-Dy intermetallic compound in eutectic $\mathrm{LiCl}-\mathrm{KCl}$
}

\author{
Wei Han, (D) *ab Zhuyao Li, ${ }^{a}$ Mei Li, ${ }^{\text {ab }}$ Yinyi Gao, ${ }^{\text {ab }}$ Xiaoguang Yang, ${ }^{\text {ab }}$ Milin Zhang ${ }^{\text {ab }}$ \\ and Yang Sun ${ }^{\mathrm{ab}}$
}

The electrochemical reduction of dysprosium(III) was studied on $\mathrm{W}$ and $\mathrm{Cu}$ electrodes in eutectic $\mathrm{LiCl}-\mathrm{KCl}$ by transient electrochemical methods. Cyclic voltammogram and current reversal chronopotentiogram results demonstrated that dysprosium(III) was directly reduced to dysprosium (0) on the W electrode through a single-step process with the transfer of three electrons. Electrochemical measurements on the $\mathrm{Cu}$ electrode showed that different $\mathrm{Cu}$-Dy intermetallics are formed. Moreover, the thermodynamic properties of $\mathrm{Cu}-\mathrm{Dy}$ intermetallic compounds were estimated by open circuit chronopotentiometry in a temperature range of 773-863 K. Using the linear polarization method, the exchange current density (jo) of dysprosium in eutectic $\mathrm{LiCl}-\mathrm{KCl}$ on the $\mathrm{Cu}$ electrode was estimated, and the temperature dependence of $j_{0}$ was studied to estimate the activation energies associated with Dy(III)/Cu 5 Dy and Dy(III)/Cug/2 Dy couples. In addition, potentiostatic electrolysis was conducted to extract dysprosium on the $\mathrm{Cu}$ electrode, and five Cu-Dy intermetallic compounds, CuDy, $\mathrm{Cu}_{2} \mathrm{Dy}, \mathrm{Cu}_{9 / 2} \mathrm{Dy}, \mathrm{Cu}_{5} \mathrm{Dy}$ and $\mathrm{Cu}_{0.99} \mathrm{Dy}_{0.01}$ were identified by X-ray diffraction, scanning electron microscopy and energy dispersive spectrometry. Meanwhile, the change of dysprosium(III) concentration was monitored using inductively coupled plasma-atomic emission spectrometry, and the maximum extraction efficiency of dysprosium was found to reach $99.2 \%$.

\section{Introduction}

Nowadays, nuclear energy is regarded as a prospective energy source for the future generation and attracts much attention due to being clean and having a high energy density. However, how to effectively manage the spent nuclear fuels in a safe and economic manner has become one of the most important problems related to the sustainable development of nuclear energy productions. Pyrometallurgical techniques, giving a drastic reduction in radioactive waste, engineering support of the fissile material nonproliferation principle and lowering of the amount reprocessing required of spent nuclear fuels, ${ }^{1}$ are a promising alternative to hydrometallurgical techniques for the recovery of actinides from spent fuels. ${ }^{2,3}$ The electrochemical deposition on the solid or liquid electrode in molten salts $^{4-6}$ or molten salts-liquid metal reductive extraction ${ }^{7,8}$ are the most developed pyrochemical methods designed for the

${ }^{a}$ Key Laboratory of Superlight Materials and Surface Technology, Ministry of Education, College of Material Science and Chemical Engineering, Harbin Engineering University, Harbin 150001, China. E-mail: weihan@hrbeu.edu.cn; Fax: +864518253 3026; Tel: +8645182569890

${ }^{b}$ Institute of Nuclear Energy and Safety, Harbin Engineering University, Harbin 150001, China separation of actinides from fission products in molten chlorides and fluoride salts.

Lanthanides are often used as surrogates because they have similar electrochemical properties to actinides. Thus, electrolytic extraction of lanthanides were carried out in chloride molten salt or fluoride molten salt systems using reactive solid cathodes, such as $\mathrm{Al},{ }^{9-11} \mathrm{Mg},{ }^{12-14} \mathrm{Ni},{ }^{15-23}$ or $\mathrm{Cu}{ }^{24-26}$ Taxil et al. ${ }^{24}$ and Gibilaro et al. ${ }^{27}$ electrochemically extracted $\mathrm{Nd}, \mathrm{Gd}, \mathrm{Sm}$ and Eu on a Ni cathode in a $\mathrm{LiF}-\mathrm{CaF}_{2}-\mathrm{LnF}_{3}(\mathrm{Ln}=\mathrm{Nd}, \mathrm{Gd}, \mathrm{Sm}$ and $\mathrm{Eu})$ molten salt system. Nourry et al. $^{26}$ investigated the electrolytic extraction of metallic $\mathrm{Nd}$ and $\mathrm{Gd}$ in $\mathrm{LiF}-\mathrm{CaF}_{2}$ melts on $\mathrm{Ni}$ and $\mathrm{Cu}$ electrodes, respectively. They found that the extraction rate on the $\mathrm{Cu}$ electrode was faster than that on $\mathrm{Ni}$ electrode in the temperature of 1113-1193 K. Our research group successfully extracted ytterbium ${ }^{28}$ and erbium $^{29}$ on a $\mathrm{Cu}$ cathode, and found that the extraction efficiencies of ytterbium and erbium on a $\mathrm{Cu}$ electrode could reach $99.9 \%$ and $98.9 \%$, respectively.

As a typical fission product element, dysprosium should be removed from actinides due to its high thermal neutron absorption cross-section. Therefore, its electrochemical separation and extraction was explored on different electrodes in molten salts. Castrillejo et al. ${ }^{30}$ researched the electrochemical behavior of dysprosium and formation of Dy-Al alloys on an $\mathrm{Al}$ electrode in the eutectic LiCl-KCl. The electrochemical production of Dy-Fe alloy films was explored on a Fe electrode 
using a molten salt electrochemical process. ${ }^{31}$ Yang et al. ${ }^{13}$ obtained the Dy-Mg alloys during selective electrochemical deposition of dysprosium on a $\mathrm{Mg}$ electrode in $\mathrm{LiCl}-\mathrm{KCl}-\mathrm{DyCl}_{3}-$ $\mathrm{GdCl}_{3}$ molten salts. Since the Dy-Ni intermetallic compounds have a magnetocaloric effect, ${ }^{32,33}$ the electrochemical preparation of Dy-Ni intermetallic compounds was explored in molten salts on a $\mathrm{Ni}$ electrode ${ }^{17,19,20,25,34,35}$ and $\mathrm{DyNi}_{2}$ electrode, ${ }^{19,34,35}$ respectively. However, $\mathrm{Cu}-\mathrm{Dy}$ alloy, as a magnetic material, ${ }^{36,37}$ has not been produced by molten salt electrolysis.

Therefore, in order for electrochemical extraction of dysprosium and formation of $\mathrm{Cu}-\mathrm{Dy}$ alloys, it is necessary to explore the kinetic properties of Dy(III) on the $\mathrm{Cu}$ electrode and the thermodynamic properties of formation of $\mathrm{Cu}-\mathrm{Dy}$ intermetallics. Thus, the electrochemical behavior of Dy(III) was first studied on the Cu electrode in eutectic LiCl-KCl using transient electrochemical techniques, for example, cyclic voltammetry (CV) and square wave voltammetry (SWV). Thermodynamic data of $\mathrm{Cu}$-Dy intermetallics were calculated by open circuit chronopotentiometry (OCP). Meanwhile, the exchange current density $\left(j_{0}\right)$ and activation energy $\left(E_{\mathrm{a}}\right)$ for Dy(III) on the $\mathrm{Cu}$ electrode were investigated by linear polarization. Then, electrochemical extraction of dysprosium and preparation of $\mathrm{Cu}-\mathrm{Dy}$ alloy were conducted on the $\mathrm{Cu}$ electrode by potentiostatic electrolysis at different electrolytic potentials. Next, the surface morphology and composition of the $\mathrm{Cu}-\mathrm{Dy}$ alloy were analyzed by SEM-EDS and XRD. Furthermore, the extraction efficiency was estimated by measuring the concentration change of Dy(III) in the melts and mass change of the working electrode.

\section{Experimental}

\section{Preparation of melts}

A mixture of LiCl-KCl with eutectic composition (45.8 : 54.2 wt\%, Anhydrous, AR, Tianjin Kermel Chemical Reagent Co., Ltd.) was dried at $553 \mathrm{~K}$ for $24 \mathrm{~h}$ to minimize the amount of residual water. Then, in order to remove the impurities in LiCl-KCl melts, pre-electrolysis was performed at $-2.1 \mathrm{~V}\left(v s \mathrm{Ag}^{+} / \mathrm{Ag}\right.$ ) for $4 \mathrm{~h}$. The temperature of the molten salt was measured with a chromel-alumel thermocouple sheathed by an alumina tube. Anhydrous $\mathrm{DyCl}_{3}$ (99.9\%; Koya fine chemicals Co., Ltd.) was introduced into the eutectic melts as the Dy(III) ions source. Moreover, to prevent the materials from reacting with oxygen or water vapor, all chemicals were operated under a high purity argon atmosphere.

\section{Electrode and electrochemical device}

The transient electrochemical techniques (CV, SWV and CP) and steady state technique (OCP) were conducted in an electrochemical cell with a three electrode set-up. All electrochemical studies were performed with the Metrohm Electrochemical Workstation (AUTOLAB PGSTAT302N) with electrochemical software (NOVA 1.10). The reference electrode is comprised of a silver wire of $1 \mathrm{~mm}$ in diameter dipped into a $\mathrm{AgCl}$ solution $(1 \mathrm{wt} \%)$ in eutectic $\mathrm{LiCl}-\mathrm{KCl}$, contained in a Pyrex tube. All potentials in this work were referenced to the $\mathrm{Ag} / \mathrm{AgCl}$ reference electrode. The auxiliary electrode was a graphite rod $(\varnothing 6.0 \mathrm{~mm})$ of spectral purity. Tungsten wire of $1 \mathrm{~mm}$ (99.99\%) in diameter, or Cu wire (99.99\%; Wantong Metal material Co., Lot; $S=0.72 \mathrm{~cm}^{2}$ ) or Cu plate (99.99\%; Wantong Metal material Co., Lot; $S=2.15 \mathrm{~cm}^{2}$ ) were used as the working electrode. The surface of the working electrode was polished with SiC paper and then washed with distilled water and alcohol, respectively.

\section{Characterization of extracting products and determination of Dy(III) concentration}

The electrochemical extraction of dysprosium was conducted on the $\mathrm{Cu}$ electrode by potentiostatic electrolysis, and then the extractive $\mathrm{Cu}-\mathrm{Dy}$ alloy was washed with distilled water and absolute ethyl alcohol (99.7\%) to remove the solidified salts attached to its surfaces. After that, the composition, morphology and micro-zone chemical analysis of extractive products were characterized by X-ray diffraction (XRD, Philips, Netherlands) and scanning electron microscope and energy dispersive spectrometer (SEM-EDS, HITACHI SU-70, Japan). The mass change of the working electrode was weighed using an electronic balance (Denver Instrument, TB-215D, $d_{60 \mathrm{~g}}=1 \times$ $10^{-5} \mathrm{~g}$ ). In order to monitor the change of Dy(III) ions concentration during the electrochemical extraction of dysprosium, a salt sample was taken out from the molten salts at various electrolysis times, and then dissolved in ultrapure water. After that, Dy(III) ions concentration in the eutectic melts was analyzed by inductively coupled plasma-atomic emission spectrometry (ICP-AES, Thermo Elemental, IRIS Intrepid II XSP) and the extraction efficiency was evaluated.

\section{Results and discussion}

\section{Electrochemical reduction of Dy(II) ions on the W electrode}

$\mathrm{CV}$ is a common electrochemical technology for investigating the electrode process and reaction mechanism, thus, it was adopted in this section to investigate the redox process of Dy(III)/ Dy on the tungsten electrode in eutectic LiCl-KCl.

Fig. 1 presents the typical cyclic voltammograms attained in eutectic LiCl-KCl before and after the addition of $\mathrm{DyCl}_{3}$ on the tungsten electrode at $773 \mathrm{~K}$. The black curve represents a typical cyclic voltammogram of the eutectic LiCl-KCl. It can be seen that only one pair of redox electrical signals $\mathrm{I} / \mathrm{I}^{\prime}$, observed at about of $-2.39 \mathrm{~V} /-2.20 \mathrm{~V}$ ( $v s$. $\mathrm{Ag} / \mathrm{AgCl}$ ), is ascribed to the deposition and re-dissolution of lithium metal.

The red curve shows the cyclic voltammogram of $\mathrm{DyCl}_{3}(1.34$ $\times 10^{-4} \mathrm{~mol} \mathrm{~cm}^{-3}$ ) in eutectic LiCl-KCl. In addition to the pair of signals $\mathrm{I} / \mathrm{I}^{\prime}$ mentioned above, a pair of new redox signals $\mathrm{II} / \mathrm{II}^{\prime}$ is detected at approximately $-2.01 \mathrm{~V} /-1.83 \mathrm{~V}$ (vs. Ag/AgCl), which are related to the reduction re-oxidation of dysprosium. No other peak signal, apart from electrical signals II/II', are found before that of the deposition of metallic lithium, suggesting that the reduction of Dy(III) is a one-step process without a codeposition reaction of $\mathrm{Li}(\mathrm{I})$ and $\mathrm{Dy}(\mathrm{III})$ ions. The results agree with those reported by Sridharan et al. ${ }^{38}$ and Shi et al. ${ }^{39}$

Current reversal chronopotentiogram of $\mathrm{DyCl}_{3}$ in $\mathrm{LiCl}-\mathrm{KCl}$ melts was recorded at $I= \pm 15 \mathrm{~mA}$, as shown in Fig. 1. The 

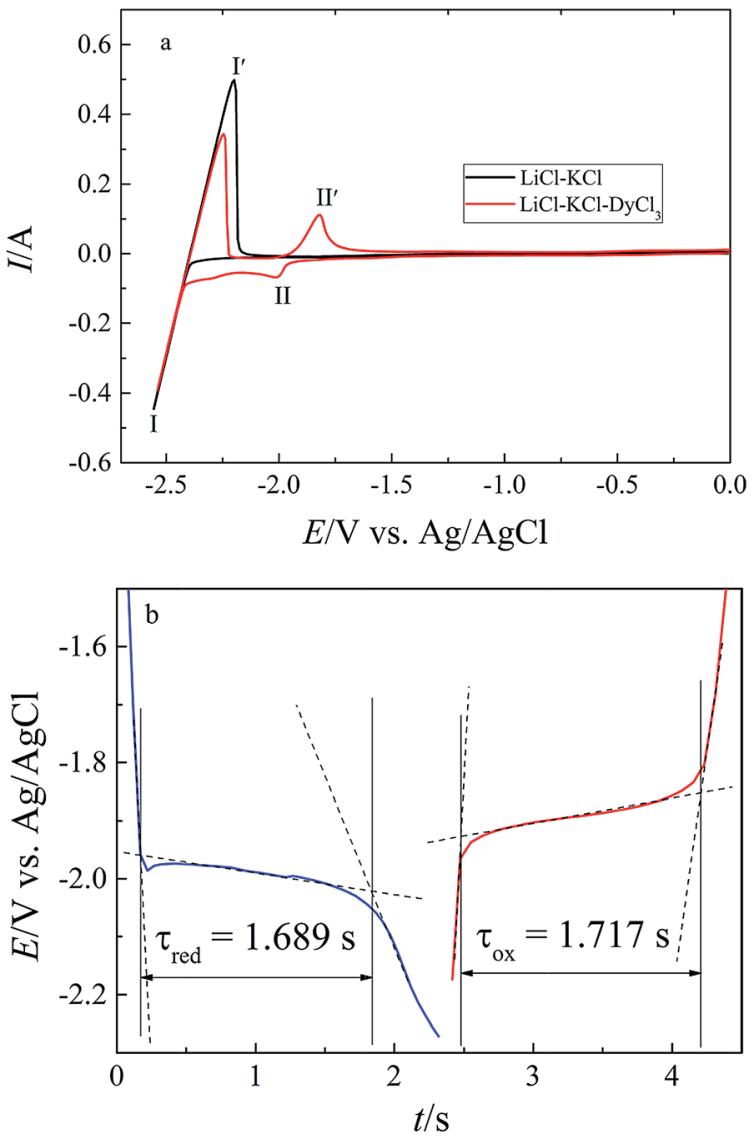

Fig. 1 (a) Cyclic voltammograms attained on the $\mathrm{W}$ electrode in the absence and presence of $\mathrm{DyCl}_{3}$ in eutectic $\mathrm{LiCl}-\mathrm{KCl}$; (b) current reversal chronopotentiogram attained on the $\mathrm{W}$ electrode in molten $\mathrm{LiCl}-\mathrm{KCl}-\mathrm{DyCl}_{3}\left(1.34 \times 10^{-4} \mathrm{~mol} \mathrm{~cm}{ }^{-3}\right)$ salts. Cathodic current: $-15 \mathrm{~mA}$; anodic current: $15 \mathrm{~mA}$; T: $773 \mathrm{~K}$. Electrode area: $0.345 \mathrm{~cm}^{2}$.

transit times ( $\tau_{\text {ed }}$ and $\left.\tau_{\text {ox }}\right)$ of the two potential plateaus $(-1.99 \mathrm{~V}$ and $-1.88 \mathrm{~V}$ ) are approximately equal, this demonstrates that electrochemical reduction of the Dy(III) process is one-step and forms insoluble metallic Dy.

$$
\mathrm{Dy}(\mathrm{III})+3 \mathrm{e}^{-}=\operatorname{Dy}(0)
$$

\section{Electrochemical reduction of Dy(III) ions on the Cu electrode}

Research results of $\mathrm{CV}$ and SWV. The comparison of cyclic voltammograms is presented in Fig. 2a, obtained in eutectic LiCl-KCl (black curve) and LiCl-KCl-DyCl $3\left(1.34 \times 10^{-4} \mathrm{~mol} \mathrm{~cm}^{-3}\right.$, red curve) melts. It can be seen from the black curve that two couples of cathodic/anodic signals are observed. Except for the cathodic/anodic signals $\mathrm{I} / \mathrm{I}^{\prime}$ corresponding to the reduction/reoxidation of metallic lithium, a new pair of signals III/III' is observed. The cathodic signal III at about $-0.27 \mathrm{~V}$ and the corresponding anodic peak III $^{\prime}$ at about $-0.11 \mathrm{~V}$ in the reverse scan direction are ascribed to the deposition and dissolution of $\mathrm{Cu}$ metal, which is found to be in line with our previous experimental results. ${ }^{28,29}$ After the addition of $\operatorname{DyCl}_{3}(1.34 \times$ $10^{-4} \mathrm{~mol} \mathrm{~cm}^{-3}$ ) into the eutectic melts, a series of cathodic/ anodic signals were observed from the red curve. In addition
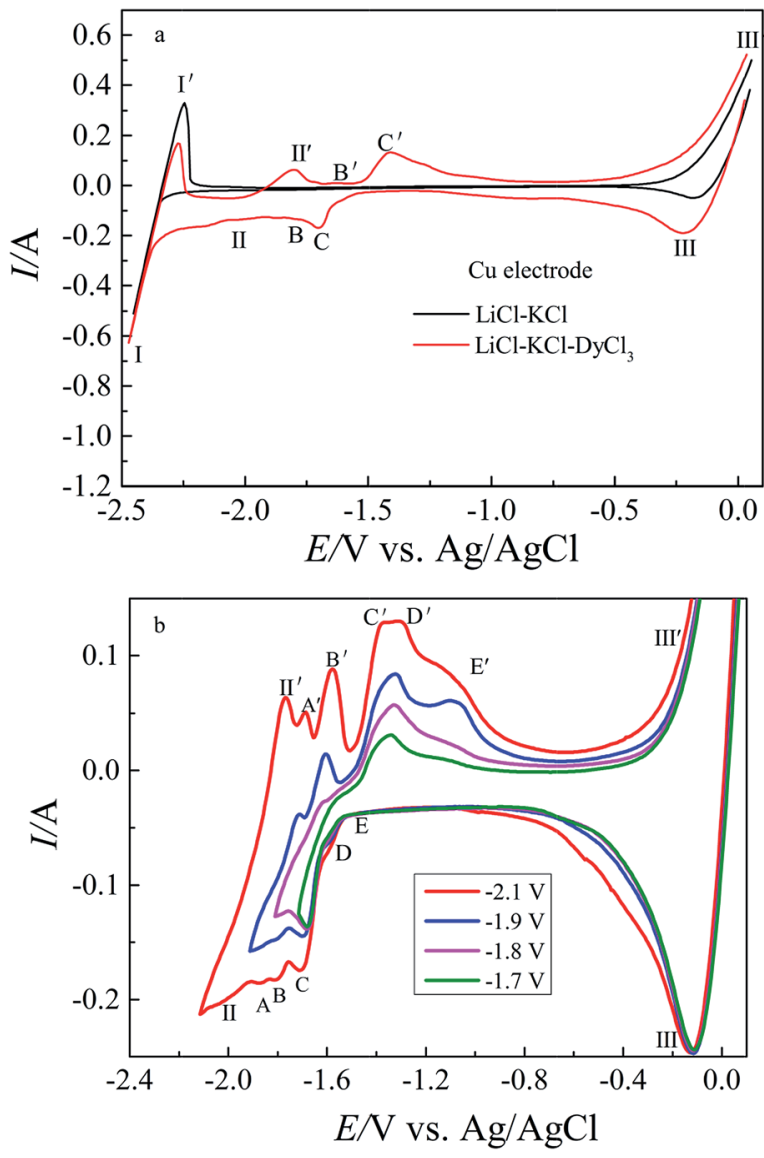

Fig. 2 (a) Cyclic voltammograms of blank eutectic $\mathrm{LiCl}-\mathrm{KCl}$ (black line) and molten $\mathrm{LiCl}-\mathrm{KCl}-\mathrm{DyCl}_{3}$ salts (red line); (b) cyclic voltammograms of molten $\mathrm{LiCl}-\mathrm{KClDyCl}_{3}$ salts at various inversion potentials. Working electrode: $\mathrm{Cu}$; electrode area: $0.72 \mathrm{~cm}^{2} ; T: 773 \mathrm{~K}$; scan rate: $0.1 \mathrm{~V} \mathrm{~s}^{-1}$

to the cathodic/anodic signals $\mathrm{I} / \mathrm{I}^{\prime}$ and III/III' mentioned above, the signals II/I' , located at $-1.98 \mathrm{~V} /-1.82 \mathrm{~V}$, are related to the reduction/re-oxidation of metallic Dy. While the other cathodic and their corresponding anodic signals, between signals II/II' and III/III', should be related to the formation/re-dissolution of different $\mathrm{Cu}$-Dy intermetallic compounds. Since deposited Dy reacts with $\mathrm{Cu}$ metal to form $\mathrm{Cu}-\mathrm{Dy}$ intermetallics, the reduction potential of the $\operatorname{Dy}(\mathrm{III}) / \mathrm{Dy}(0)$ couple is detected at less negative potential values than that on the $\mathrm{W}$ electrode. The formation of $\mathrm{Cu}-\mathrm{Dy}$ intemetallic compounds is described as follows:

$$
\mathrm{Dy}(\mathrm{III})+3 \mathrm{e}^{-}+x \mathrm{Cu}=\mathrm{Cu}_{x} \text { Dy }
$$

For confirming the attribution of these redox peaks, the cyclic voltammograms were registered at different reversion potentials as shown in Fig. 2b. It is obvious that five pairs of redox signals, $\mathrm{A} / \mathrm{A}^{\prime}, \mathrm{B} / \mathrm{B}^{\prime}, \mathrm{C} / \mathrm{C}^{\prime}, \mathrm{D} / \mathrm{D}^{\prime}$ and $\mathrm{E} / \mathrm{E}^{\prime}$ observed at -1.86 $\mathrm{V} /-1.67 \mathrm{~V},-1.80 \mathrm{~V} /-1.57 \mathrm{~V},-1.71 \mathrm{~V} /-1.37 \mathrm{~V},-1.58 \mathrm{~V} /-1.28 \mathrm{~V}$ and $-1.45 /-1.08 \mathrm{~V}$, are correlated with the formation and dissolution of five $\mathrm{Cu}-\mathrm{Dy}$ intermetallics. Based on the phase 
diagram of the $\mathrm{Cu}$-Dy binary system, ${ }^{\mathbf{4 0 , 4 1}}$ there are four thermodynamically stable $\mathrm{Cu}-\mathrm{Dy}$ intermetallics (CuDy, $\mathrm{Cu}_{2} \mathrm{Dy}$, $\mathrm{Cu}_{9 / 2}$ Dy and $\mathrm{Cu}_{5} \mathrm{Dy}$ ). Thus, we suggested that the thermodynamically metastable phase might form under such conditions.

Fig. 3 shows the SWV recorded on the Cu electrode in molten LiCl-KCl-DyCl $3\left(1.34 \times 10^{-4} \mathrm{~mol} \mathrm{\textrm {cm } ^ { - 3 }}\right)$ salts at various frequencies. It is clear that these cathodic peak currents increase with the increase of frequency. As seen from Fig. 3, there are eight reductive peaks observed in the electrochemical window. Based on the results shown in Fig. 2, the attribution of eight reduction signals could be confirmed. Three reduction peaks I, II and III, detected at $-2.40 \mathrm{~V},-2.04 \mathrm{~V}$ and $-0.24 \mathrm{~V}$, respectively, are ascribed to the deposition of metallic $\mathrm{Li}$, Dy and $\mathrm{Cu}$, respectively. The other five reduction current peaks $\mathrm{A}$, B, C, D and E observed at $-1.88 \mathrm{~V},-1.79 \mathrm{~V},-1.68 \mathrm{~V},-1.59 \mathrm{~V}$ and $-1.44 \mathrm{~V}$, respectively, are ascribed to the deposition of metallic Dy on the $\mathrm{Cu}$ electrode to form five different $\mathrm{Cu}-\mathrm{Dy}$ intermetallic compounds. Comparison of the reduction peak potentials obtained by CV and SWV are presented in Table 1. It can be seen from Table 1 that the results gained by $\mathrm{CV}$ are consistent with those obtained by SWV.

Research results of OCP. As a steady state technique, OCP is commonly used to obtain the equilibrium potential of formation for different intermetallics. Therefore, OCP was employed on the $\mathrm{Cu}$ electrode in molten $\mathrm{LiCl}-\mathrm{KCl}-\mathrm{DyCl}_{3}$ salts at different temperatures. The measurement was conducted as follows: after a short cathodic polarization at $-2.5 \mathrm{~V}(v s . \mathrm{Ag} / \mathrm{AgCl})$ for $50 \mathrm{~s}$ at $773 \mathrm{~K}$, metallic Dy was firstly electrodeposited on the $\mathrm{Cu}$

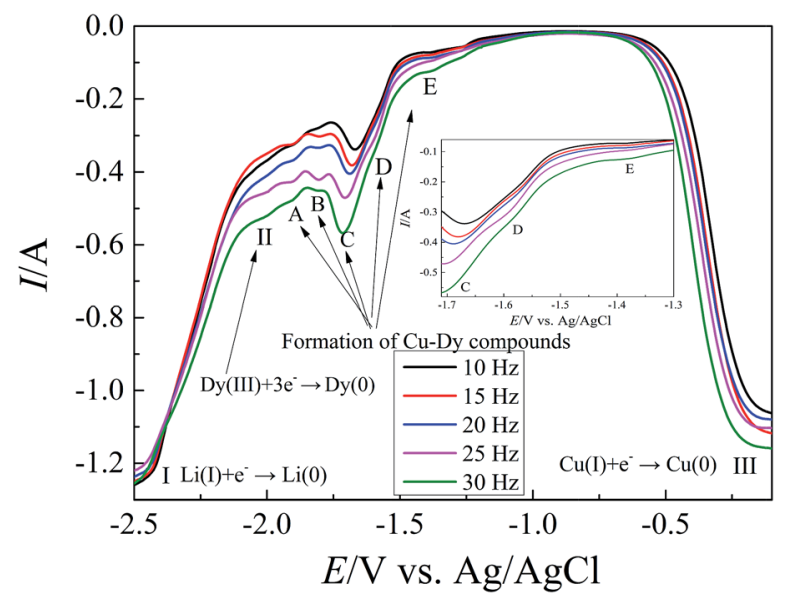

Fig. 3 Square wave voltammograms attained in molten $\mathrm{LiCl}-\mathrm{KCl}-$ $\operatorname{DyCl}_{3}\left(1.34 \times 10^{-4} \mathrm{~mol} \mathrm{~cm}^{-3}\right)$ salts on a Cu electrode $\left(S=0.72 \mathrm{~cm}^{2}\right)$ at $773 \mathrm{~K}$. Potential step: $1 \mathrm{mV}$; frequency: $10-30 \mathrm{~Hz}$.

Table 1 Summary of the peak potentials obtained by different electrochemical techniques

\begin{tabular}{|c|c|c|c|c|c|c|c|}
\hline \multirow{2}{*}{$\begin{array}{l}\text { Electrochemical } \\
\text { techniques }\end{array}$} & \multicolumn{7}{|c|}{ Reduction peak potentials/V } \\
\hline & II & A & B & $\mathrm{C}$ & $\mathrm{D}$ & $\mathrm{E}$ & III \\
\hline $\mathrm{CV}$ & -2.02 & -1.86 & -1.80 & -1.71 & -1.58 & -1.45 & -0.11 \\
\hline $\mathrm{Hz}$ SWV & -2.00 & -1.88 & -1.79 & -1.68 & -1.59 & -1.44 & -0.14 \\
\hline
\end{tabular}

electrode. After stopping the polarization, the $\mathrm{Cu}$ electrode was kept in the melts. During the currentless process, the open circuit potential was registered vs. time. A series of potential plateaus occur in the open circuit chronopotentiogram and each potential plateau is related to a two-phase coexistence state on the $\mathrm{Cu}$ electrode surface.

Fig. 4a (black curve) shows the open circuit chronopotentiogram detected on the $\mathrm{Cu}$ electrode after a short cathodic polarization at $-2.5 \mathrm{~V}(\mathrm{Ag} / \mathrm{AgCl})$ for $80 \mathrm{~s}$ in molten LiCl-KCl-DyCl $3\left(1.34 \times 10^{-4} \mathrm{~mol} \mathrm{~cm}^{-3}\right)$ salts at $773 \mathrm{~K}$. It can be seen that there are seven potential plateaus in the black curve. To confirm the ascription of the potential plateau, the open circuit chronopotentiograms of eutectic LiCl-KCl (blue curve) on the $\mathrm{Cu}$ electrode and molten $\mathrm{LiCl}-\mathrm{KCl}-\mathrm{DyCl}_{3}$ salt (red curve) on the $\mathrm{W}$ electrode are also presented in Fig. 4a after potentiostatic electrolysis at $-2.5 \mathrm{~V}$ for $80 \mathrm{~s}$. Based on the results of CV and SWV (shown in Fig. 2 and 3), the first plateau I occurs near $-2.42 \mathrm{~V}$ interpreted due to the formation of metallic $\mathrm{Li}$ on the $\mathrm{Cu}$ electrode and correlated with the redox couple of $\mathrm{Li}(\mathrm{I}) / \mathrm{Li}(0)$.

The second plateau II observed at about $-1.90 \mathrm{~V}$ is related to the equilibrium of the $\mathrm{Dy}(\mathrm{III}) / \mathrm{Dy}(0)$ redox couple. After that,
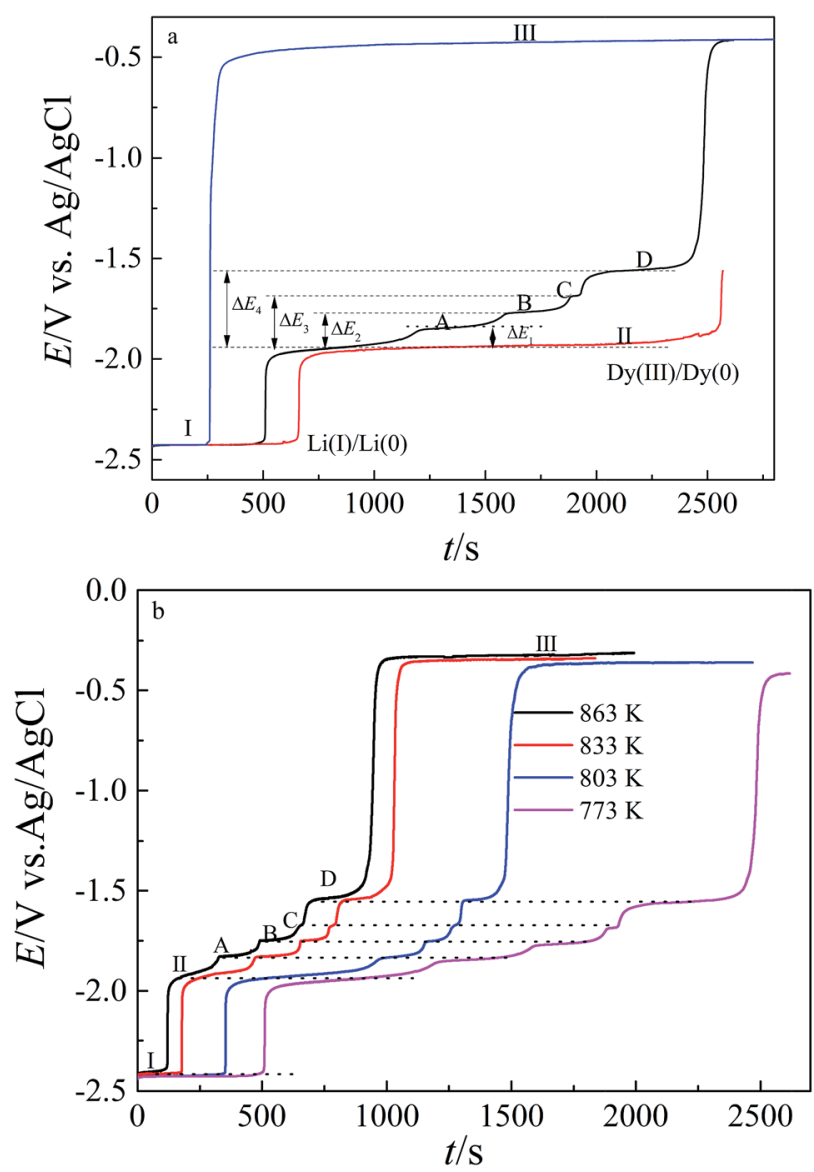

Fig. 4 (a) Open circuit chronopotentiograms recorded in molten $\mathrm{LiCl}-\mathrm{KCl}-\mathrm{DyCl}_{3}$ (red line) salts on $\mathrm{W}$ electrode $\left(S=0.345 \mathrm{~cm}^{2}\right.$ ), eutectic $\mathrm{LiCl}-\mathrm{KCl}$ (blue line) and molten $\mathrm{LiCl}-\mathrm{KCl}-\mathrm{DyCl}_{3}$ (black line) salts on a $\mathrm{Cu}$ electrode $\left(S=0.72 \mathrm{~cm}^{2}\right)$ at $773 \mathrm{~K}$ and (b) open circuit chronopotentiograms recorded on $\mathrm{Cu}$ electrode $\left(S=0.72 \mathrm{~cm}^{2}\right)$ in molten $\mathrm{LiCl}-\mathrm{KCl}-\mathrm{DyCl}_{3}$ salts at different temperature. Deposition potential: $-2.5 \mathrm{~V}$; time: $80 \mathrm{~s}$. 
Table 2 Thermodynamic properties of Dy for Cu-Dy intermetallic compounds in two-phase coexisting states at different temperatures

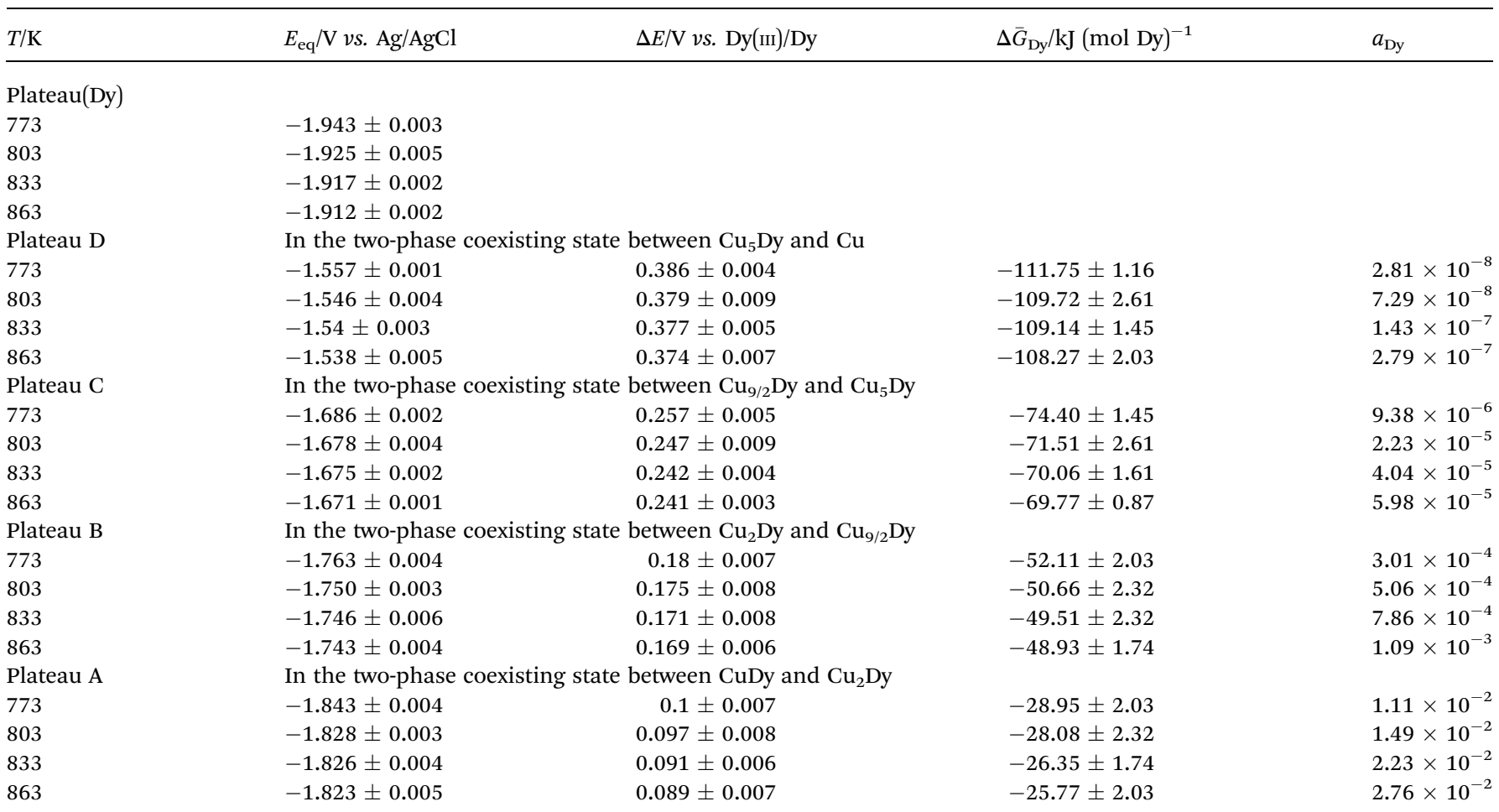

there are four potential plateaus A, B, C and D. There are four $\mathrm{Cu}$-Dy intermetallics, CuDy, $\mathrm{Cu}_{2}$ Dy, $\mathrm{Cu}_{9 / 2}$ Dy and $\mathrm{Cu}_{5}$ Dy, in the system, ${ }^{\mathbf{4 0 , 4 1}}$ thus, the four potential plateaus should correlate with the co-existence of two phases of four $\mathrm{Cu}$-Dy intermetallics, respectively. Furthermore, according to the result, we inferred that the reduction signal E in the CV (Fig. 2) and SWV (Fig. 3) is ascribed to the formation of a metastable phase of the $\mathrm{Cu}$-Dy intermetallics. The last potential plateau III observed at about $-0.28 \mathrm{~V}$ corresponds to the equilibrium of $\mathrm{Cu}(\mathrm{I}) / \mathrm{Cu}$ according to the results reported by Castrillejo et al. $^{\mathbf{4 2}}$
Therefore, each potential plateau correlated with the equilibrium reaction can be expressed as follows:

$$
\begin{gathered}
\text { Plateau I: } \mathrm{Li}(\mathrm{I})+\mathrm{e}^{-} \leftrightarrow \mathrm{Li} \\
\text { Plateau II: Dy(III) }+3 \mathrm{e}^{-} \leftrightarrow \text { Dy } \\
\text { Plateau D: Dy(III) }+3 \mathrm{e}^{-}+5 \mathrm{Cu} \leftrightarrow \mathrm{Cu}_{5} \text { Dy } \\
\text { Plateau C: Dy(III) }+3 \mathrm{e}^{-}+9 \mathrm{Cu}_{5} \text { Dy } \leftrightarrow 10 \mathrm{Cu}_{9 / 2} \text { Dy }
\end{gathered}
$$

\begin{tabular}{|c|c|c|c|}
\hline $\begin{array}{l}\text { Intermetallic } \\
\text { compound }\end{array}$ & Formula & $T / \mathbf{K}$ & $\Delta G_{\mathrm{f}}^{\ominus} / \mathrm{kJ} \mathrm{mol}^{-1}$ \\
\hline \multirow[t]{4}{*}{$\mathrm{Cu}_{5} \mathrm{Dy}$} & \multirow[t]{4}{*}{$\Delta G_{\mathrm{f}}^{\ominus}\left(\mathrm{Cu}_{5} \mathrm{Dy}\right)=-3 F \Delta E_{4}$} & 773 & $-111.75 \pm 1.16$ \\
\hline & & 803 & $-109.72 \pm 2.61$ \\
\hline & & 833 & $-109.14 \pm 1.45$ \\
\hline & & 863 & $-108.27 \pm 2.03$ \\
\hline \multirow[t]{4}{*}{$\mathrm{Cu}_{9 / 2} \mathrm{Dy}$} & \multirow{4}{*}{$\Delta G_{\mathrm{f}}^{\ominus}\left(\mathrm{Cu}_{9 / 2} \mathrm{Dy}\right)=\frac{1}{10}\left[9 \Delta G_{\mathrm{f}}^{\ominus}\left(\mathrm{Cu}_{5} \mathrm{Dy}\right)-3 F \Delta E_{3}\right]$} & 773 & $-108.01 \pm 1.19$ \\
\hline & & 803 & $-105.89 \pm 2.61$ \\
\hline & & 833 & $-105.23 \pm 1.42$ \\
\hline & & 863 & $-104.42 \pm 1.91$ \\
\hline \multirow[t]{4}{*}{$\mathrm{Cu}_{2} \mathrm{Dy}$} & \multirow{4}{*}{$\Delta G_{\mathrm{f}}^{\ominus}\left(\mathrm{Cu}_{2} \mathrm{Dy}\right)=\frac{5}{9}\left[\frac{4}{5} \Delta G_{\mathrm{f}}^{\ominus}\left(\mathrm{Cu}_{9 / 2} \mathrm{Dy}\right)-3 F \Delta E_{2}\right]$} & 773 & $-76.96 \pm 1.65$ \\
\hline & & 803 & $-75.21 \pm 2.45$ \\
\hline & & 833 & $-74.27 \pm 1.92$ \\
\hline & & 863 & $-73.59 \pm 1.81$ \\
\hline \multirow[t]{4}{*}{ CuDy } & \multirow{4}{*}{$\Delta G_{\mathrm{f}}^{\ominus}(\mathrm{CuDy})=\frac{1}{2}\left[\Delta G_{\mathrm{f}}^{\ominus}\left(\mathrm{Cu}_{2} \mathrm{Dy}\right)-3 F \Delta E_{1}\right]$} & 773 & $-52.95 \pm 1.84$ \\
\hline & & 803 & $-51.65 \pm 2.38$ \\
\hline & & 833 & $-50.31 \pm 1.83$ \\
\hline & & 863 & $-49.68 \pm 1.92$ \\
\hline
\end{tabular}

Table 3 Standard Gibbs free energies of formation for Cu-Dy intermetallic compounds 


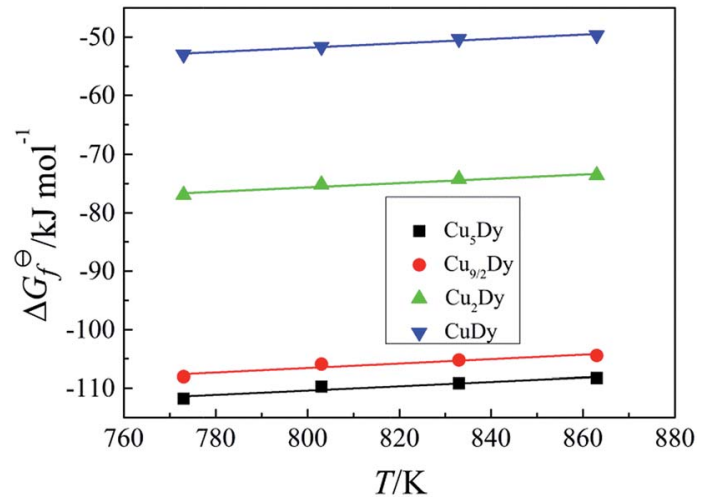

Fig. 5 Change of Gibbs energies of formation for different Cu-Dy intermetallic compounds with temperature.

$$
\begin{aligned}
& \text { Plateau B : Dy(III) }+3 \mathrm{e}^{-}+\frac{4}{5} \mathrm{Cu}_{9 / 2} \mathrm{Dy} \leftrightarrow \frac{9}{5} \mathrm{Cu}_{2} \mathrm{Dy} \\
& \text { Plateau A: Dy(III) }+3 \mathrm{e}^{-}+\mathrm{Cu}_{2} \mathrm{Dy} \leftrightarrow 2 \mathrm{CuDy}
\end{aligned}
$$

Fig. 4b illustrates the open circuit chronopotentiograms recorded in molten $\mathrm{LiCl}-\mathrm{KCl}-\mathrm{DyCl}_{3}$ salts after potentiostatic deposition at $-2.5 \mathrm{~V}$ for $80 \mathrm{~s}$ at different temperatures. To ensure the reproducibility of the results of the OCP, the measurement was carried out several times under the same conditions. As can be seen from Fig. 4, the plateau length, correlated with the corresponding equilibrium reaction, grows shorter with an increase of temperature at the same conditions, which indicates that the dissolving rate of $\mathrm{Cu}$-Dy intermetallics increases with the increasing of temperature.

The equilibrium potentials in this experiment are referred to the $\mathrm{Ag}^{+} / \mathrm{Ag}$ couple, thus, these can be converted to the electromotive forces (emf) against $\mathrm{Dy}(0)$. The potential values $(\Delta E v s$. Dy(III)/Dy) are obtained at various temperatures and listed in Table 2.

On the basis of the value of $\Delta E v s$. $(\mathrm{Dy}(\mathrm{III}) / \mathrm{Dy}(0)) / \mathrm{V}$, the activities and the partial molar Gibbs free energy $\left(\Delta \bar{G}_{\text {Dy }}\right)$ of Dy in various $\mathrm{Cu}-\mathrm{Dy}$ intermetallics are estimated by the following equation:

$$
\mathrm{emf}=\Delta E=-(R T / 3 F) \ln a_{\mathrm{Dy}}=-\Delta \bar{G}_{\mathrm{Dy}} / 3 F
$$

The calculated results are also presented in Table 2. As can be seen from Table 2, the activity values of $\mathrm{Dy}$ in $\mathrm{Cu}-\mathrm{Dy}$ alloys are in the order of $10^{-8}$ to $10^{-2}$.
When the two phase equilibrium of $\mathrm{CuDy}_{x_{1}}$ and $\mathrm{CuDy}_{x_{2}}$ exists on the $\mathrm{Cu}$ electrode surface, the emf has a constant value during the whole transformation of $\mathrm{CuDy}_{x 1}$ into the $\mathrm{CuDy}_{x 2}$. For an intermetallic compound with exact composition, $\mathrm{CuDy}_{x_{2}}$ for example, it can be observed that a variation of the emf from the value of the two phase plateau is related to the mixture of $\mathrm{CuDy}_{x_{1}}$ and $\mathrm{CuDy}_{x_{2}}$ to the value of the two phase plateau of the $\mathrm{CuDy}_{x 2}$ and $\mathrm{CuDy}_{x 3}$ mixture. The standard Gibbs energies of formation for an intermetallic compound $\mathrm{CuDy}_{x_{2}}$ are related to that of $\mathrm{CuDy}_{x 1}$ by the relation:

$$
\Delta G_{\mathrm{f}}^{\ominus}\left(\mathrm{CuDy}_{x 2}\right)=-3 F \int_{x 1}^{x 2} \Delta E(x) \mathrm{d} x+\Delta G_{\mathrm{f}}^{\ominus}\left(\mathrm{CuDy}_{x 1}\right)
$$

The calculated formulas of standard molar Gibbs free energies of formation for different $\mathrm{Cu}$-Dy intermetallic compounds and results are presented in Table 3.

The change of standard molar Gibbs free energy of formation for various $\mathrm{Cu}$-Dy intermetallics with temperature is shown in Fig. 5. The standard molar enthalpies of formation and standard molar entropies, as well as the standard equilibrium constant of formation of each of the $\mathrm{Cu}$-Dy intermetallics are obtained based on the slope of the linear relationship, and the results are listed in Table 4.

Palumbo et al. ${ }^{41}$ determined the standard mole enthalpy of formation for $\mathrm{Cu}_{5} \mathrm{Dy}$ intermetallics by high-temperature direct calorimetry in the temperature range of 298-3000 K. They found the value to be $-116.4 \mathrm{~kJ} \mathrm{~mol}^{-1}$, which is slightly less than our result. Sommer et al. ${ }^{43}$ measured the standard mole enthalpy of formation for the $\mathrm{Cu}_{9 / 2} \mathrm{Dy}$ intermetallic compound by solution calorimetry at $1098 \mathrm{~K}$ and the calculated result is $-121 \pm$ $2.2 \mathrm{~kJ} \mathrm{~mol}^{-1}$, which is smaller than our result. The difference may be related to the difference of experimental methods and existence states of the $\mathrm{Cu}$-Dy intermetallic compounds.

Research results of LP. The exchange current density is an important kinetics parameter, related to the nucleation characteristics and morphology of electrodeposits. Thus, the linear polarization (LP) technique was carried out to determine the exchange current density $\left(j_{0}\right)$ of dysprosium on the $\mathrm{Cu}$ electrode. At very low overpotentials, the Butler-Volmer equation ${ }^{44}$ can be simplified to the following expression:

$$
j / \eta=j_{0}(n F / R T)
$$

where $j$ is the net current density, $j_{0}$ denotes the exchange current density, and $\eta=E-E_{\mathrm{eq}}$ is the overpotential defined

Table 4 Thermodynamic properties of Cu-Dy intermetallic compounds

\begin{tabular}{lllll}
$\begin{array}{l}\text { Intermetallic } \\
\text { compound }\end{array}$ & $\Delta H_{\mathrm{f}}^{\ominus} / \mathrm{kJ} \mathrm{mol}^{-1}$ & $\Delta S_{\mathrm{f}}^{\ominus} / \mathrm{J} \mathrm{mol}^{-1} \mathrm{~K}^{-1}$ & $\Delta G_{\mathrm{f}}^{\ominus}(T) / \mathrm{kJ} \mathrm{mol}^{-1}$ & $K^{\ominus}$ \\
\hline $\mathrm{Cu}_{5} \mathrm{Dy}$ & $-139.72 \pm 2.14$ & $-36.67 \pm 0.0048$ & $-139.72+0.036 T$ & $\exp (-4.33+1685 / T)$ \\
& -116.4 (ref. 41$)$ & $-38.12 \pm 0.0016$ & $-137.07+0.038 T$ & \\
$\mathrm{Cu}_{9 / 2}$ Dy & $-137.07 \pm 0.43$ & & & \\
& $-121 \pm 2.2($ ref. 43$)$ & $-36.78 \pm 0.0002$ & $-105.09+0.036 T$ & $\exp (-4.57+16486 / T)$ \\
$\mathrm{Cu}_{2}$ Dy & $-105.09 \pm 2.09$ & $-37.21 \pm 0.001$ & $-81.58+0.037 T$ & $\exp (-4.33+12641 / T)$ \\
$\mathrm{CuDy}$ & $-81.58 \pm 2.84$ & &
\end{tabular}


with respect to a specific reaction. In this study, the exchange current densities were determined for Dy(III)/Cu${ }_{5}$ Dy and Dy(III)/ $\mathrm{Cu}_{9 / 2}$ Dy couples by the LP technique.

Fig. 6 shows the cathodic polarization curves obtained at the equilibrium potential of $\mathrm{Dy}(\mathrm{III}) / \mathrm{Cu}_{5} \mathrm{Dy}$ and $\mathrm{Dy}(\mathrm{III}) / \mathrm{Cu}_{9 / 2} \mathrm{Dy}$ couples, respectively, in $\mathrm{LiCl}-\mathrm{KCl}-\mathrm{DyCl}_{3}$ melts on the $\mathrm{Cu}$ electrode at a scan rate of $2 \mathrm{mV} \mathrm{s}^{-1}$ and $\pm 15 \mathrm{mV}$ (Fig. 6a) and $\pm 13 \mathrm{mV}$ (Fig. 6b) overpotentials. According to the slope of the fitted line, the values of $j_{0}$ were calculated and are presented in Fig. 7. The exchange current density for the $\mathrm{Dy}(\mathrm{III}) / \mathrm{Cu}_{9 / 2} \mathrm{Dy}$ couple was found to be higher than that for the Dy(III) $/ \mathrm{Cu}_{5} \mathrm{Dy}$ couple. Fig. 8 shows the plot of $\ln \left(j_{0}\right)$ versus inverse temperature. The variation of $j_{0}$ with temperature was found to follow the
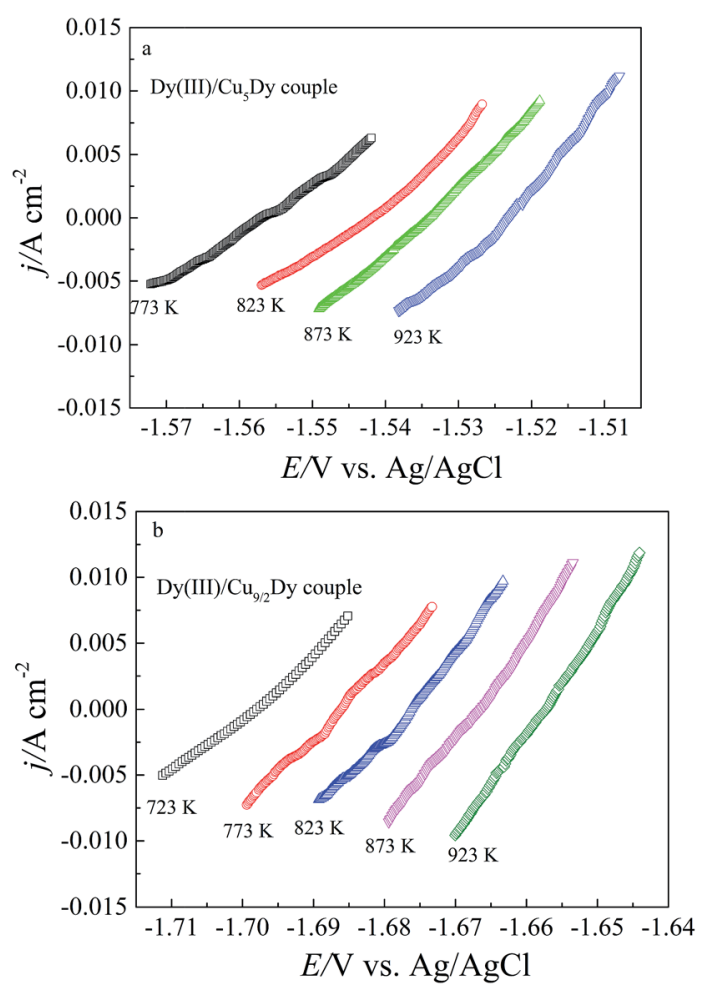

Fig. 6 Cathodic polarization curves by linear polarization of Dy on the $\mathrm{Cu}$ cathode in $\mathrm{LiCl}-\mathrm{KCl}$ eutectic at different polarization potentials.

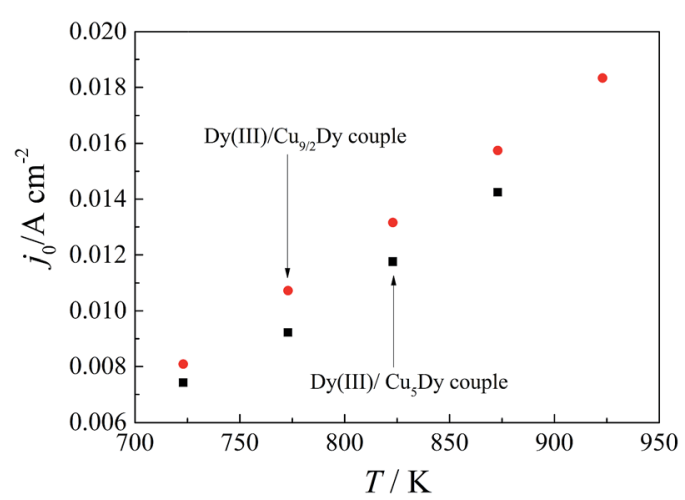

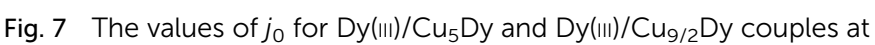
different temperatures.
Arrhenius law, from which the activation energies associated with the equilibrium reactions were determined. It can be seen that the activation energies for the $\mathrm{Dy}(\mathrm{III}) / \mathrm{Cu}_{5} \mathrm{Dy}$ and $\mathrm{Dy}(\mathrm{III}) /$ $\mathrm{Cu}_{9 / 2}$ Dy couples are $26.08 \mathrm{~kJ} \mathrm{~mol}^{-1}$ and $22.55 \mathrm{~kJ} \mathrm{~mol}^{-1}$, respectively. The activation energy for the Dy(III) $/ \mathrm{Cu}_{5}$ Dy couple is higher than that for the Dy(III)/ $\mathrm{Cu}_{9 / 2}$ Dy couple.

\section{Electroextraction and characterization of $\mathrm{Cu}-\mathrm{Dy}$ alloys}

In order to extract dysprosium and prepare $\mathrm{Cu}-\mathrm{Dy}$ alloys on the $\mathrm{Cu}$ electrode, according to the results of the CV, SWV and OCP
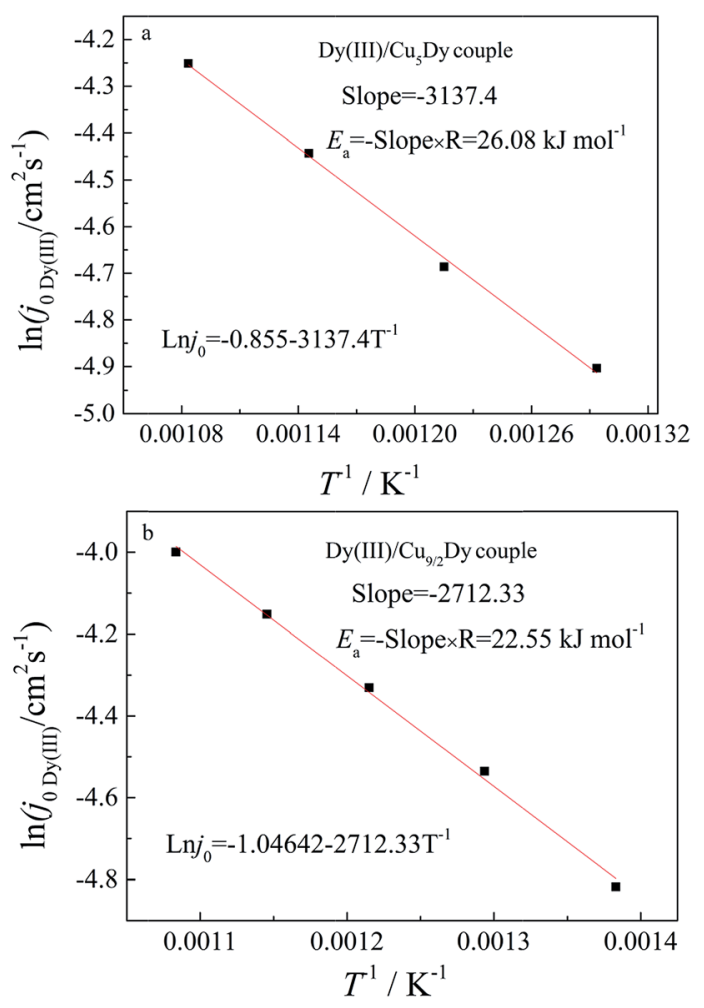

Fig. 8 The change of $\ln \left(j_{0}\right)$ versus inverse temperature.

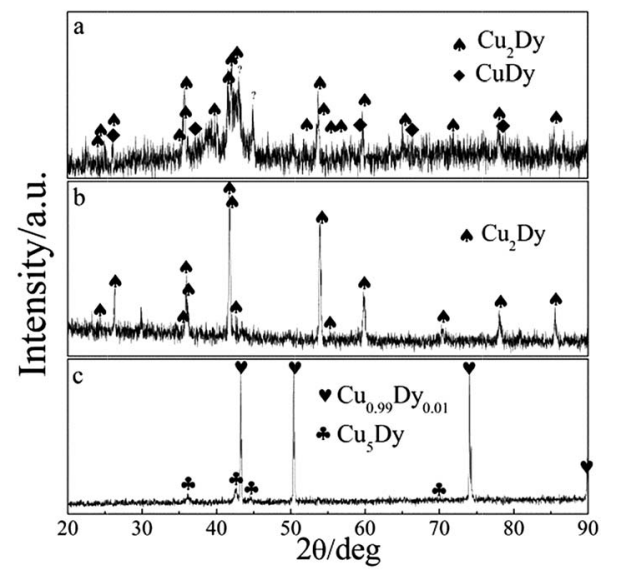

Fig. 9 XRD patterns of the deposits obtained on the Cu electrode $(S=$ $2.15 \mathrm{~cm}^{2}$ ) in molten $\mathrm{LiCl}-\mathrm{KCl}-\mathrm{DyCl}_{3}$ salts for $7 \mathrm{~h}$ at $773 \mathrm{~K}$ by potentiostatic electrolysis at (a) $-2.15 \mathrm{~V}$, (b) $-1.77 \mathrm{~V}$ and (c) $-1.55 \mathrm{~V}$. 
(Fig. 2-4), potentiostatic electrolysis was conducted at different potentials on the $\mathrm{Cu}$ electrode.

Fig. 9 shows the XRD patterns of extractive productions after potentiostatic electrolysis at $-2.15 \mathrm{~V}(\mathrm{a}),-1.77 \mathrm{~V}(\mathrm{~b})$ and $-1.55 \mathrm{~V}$ (c) at $773 \mathrm{~K}$ on the Cu electrode in LiCl-KCl-DyCl ${ }_{3}(1.34$ $\times 10^{-4} \mathrm{~mol} \mathrm{~cm}^{-3}$ ) melts, respectively. When the potentiostatic electrolysis was performed at $-2.15 \mathrm{~V}$, metallic dysprosium is deposited and diffuses into the $\mathrm{Cu}$ substrate. Thus, all $\mathrm{Cu}-\mathrm{Dy}$ intermetallic compounds of the binary system can be expected. However, only two intermetallic compounds $\mathrm{Cu}_{2}$ Dy and CuDy are characterized by XRD analysis (Fig. 9a) in the alloy layer. While when the potentiostatic electrolysis was conducted at
$-1.77 \mathrm{~V}$, only one $\mathrm{Cu}$-Dy intermetallic compound, $\mathrm{Cu}_{2} \mathrm{Dy}$, is formed. However, at $-1.55 \mathrm{~V}$, two intermetallic compounds $\mathrm{Cu}_{5}$ Dy and $\mathrm{Cu}_{0.99} \mathrm{Dy}_{0.01}$ are prepared. According to the $\mathrm{Cu}-\mathrm{Dy}$ phase diagram, ${ }^{\mathbf{4 0 , 4 1}}$ there are four thermodynamically stable $\mathrm{Cu}-$ Dy intermetallics (CuDy, $\mathrm{Cu}_{2}$ Dy, $\mathrm{Cu}_{9 / 2}$ Dy and $\mathrm{Cu}_{5}$ Dy) in the system. Since there isn't a $\mathrm{Cu}_{0.99} \mathrm{Dy}_{0.01}$ phase in the thermodynamically stable phases, we infer that $\mathrm{Cu}_{0.99} \mathrm{Dy}_{0.01}$ is the metastable phase.

Fig. 10 shows the SEM-EDS of the deposit attained by potentiostatic electrolysis at $-2.15 \mathrm{~V}$ for $7 \mathrm{~h}$ on the $\mathrm{Cu}$ electrode at $773 \mathrm{~K}$ in the molten LiCl-KCl-DyCl $3\left(1.34 \times 10^{-4} \mathrm{~mol} \mathrm{~cm}^{-3}\right)$ salts. The thickness of the deposited layer is approximately
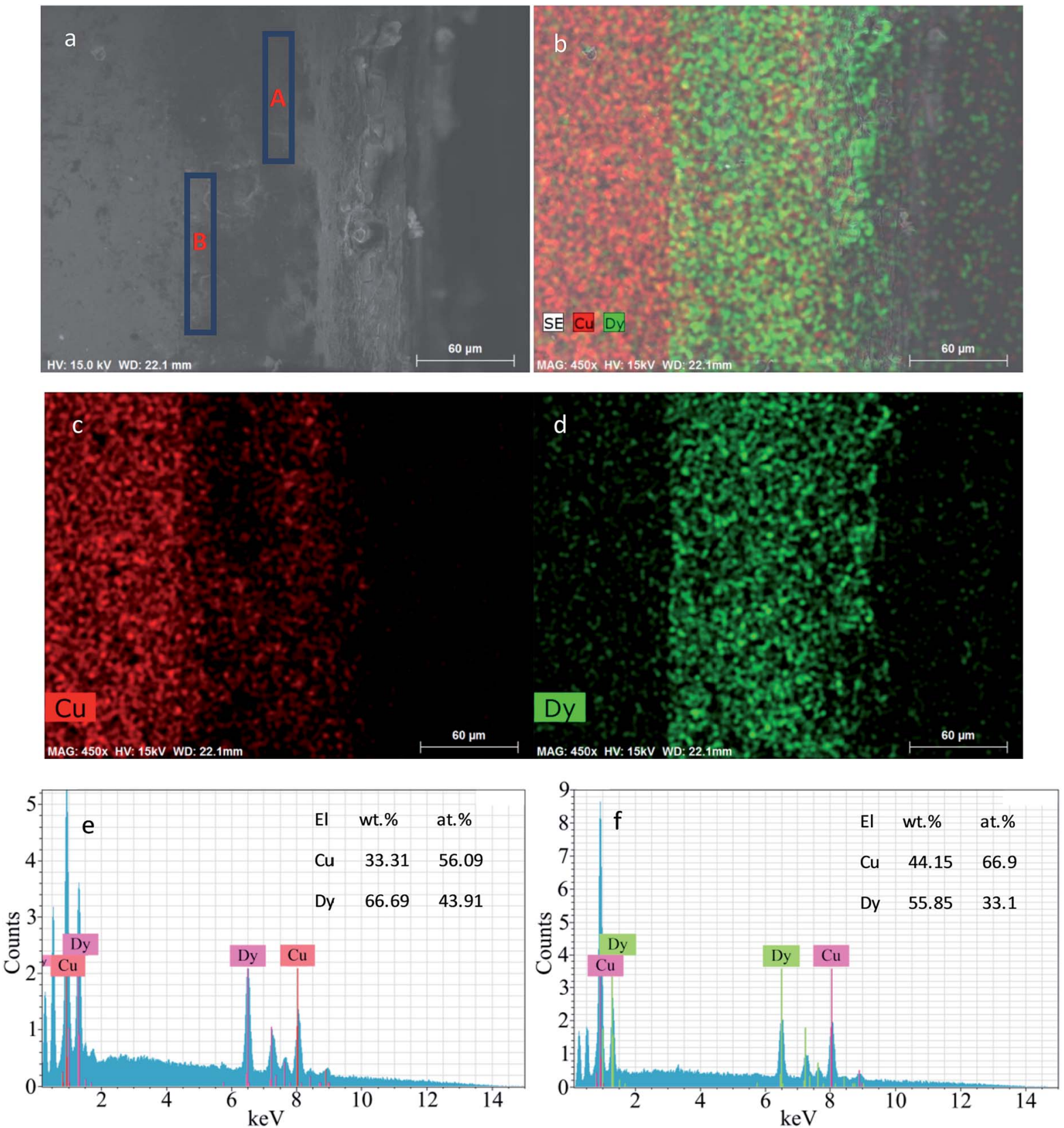

Fig. $10 \mathrm{SEM}$-EDS of deposit obtained by potentiostatic electrolysis at $-2.15 \mathrm{~V}$ on the $\mathrm{Cu}\left(\mathrm{S}=2.15 \mathrm{~cm}^{2}\right)$ electrode in molten $\mathrm{LiCl}-\mathrm{KCl}-\mathrm{DyCl}$ salts for $7 \mathrm{~h}$ at 773 K. (a) SEM; (b)-(d) EDS mapping analysis; (e) and (f) EDS point analysis of zones A and B shown in (a). 
$80 \mu \mathrm{m}$ (Fig. 10a). As can be seen from the mapping analysis of the elements (Fig. 10b-d), that the deposit mainly consists of $\mathrm{Cu}$ and Dy. The atomic ratio of $\mathrm{Cu}$ to Dy in zones A and B shown in Fig. 10a are close to $1: 1$ and $2: 1$, respectively (Fig. 10e and f). Combined with the XRD result (Fig. 9a), we think that the alloy layer is comprised of $\mathrm{Cu}_{2} \mathrm{Dy}$ and $\mathrm{CuDy}$ intermetallic compounds.

Fig. 11 displays the SEM-EDS analysis of the $\mathrm{Cu}-\mathrm{Dy}$ alloy sample prepared by potentiostatic electrolysis at $-1.77 \mathrm{~V}$ for $7 \mathrm{~h}$ on the $\mathrm{Cu}$ electrode at $773 \mathrm{~K}$ in the molten $\mathrm{LiCl}-\mathrm{KCl}-\mathrm{DyCl}_{3}$ $\left(1.34 \times 10^{-4} \mathrm{~mol} \mathrm{~cm}^{-3}\right)$. The thickness of the alloy layer is about $60 \mu \mathrm{m}$ (Fig. 11a-c). The atomic ratio of $\mathrm{Cu}$ to Dy in zone A shown in Fig. 11a is close to $2: 1$ (Fig. 11d). Combined with the XRD result (Fig. 9b), we infer that the alloy layer consists of the $\mathrm{Cu}_{2} \mathrm{Dy}$ intermetallic compound.

Fig. 12 illustrates the SEM-EDS analysis of the Cu-Dy alloy produced by potentiostatic electrolysis at $-1.7 \mathrm{~V}$ for $7 \mathrm{~h}$ on the $\mathrm{Cu}$ electrode at $773 \mathrm{~K}$ in the molten $\mathrm{LiCl}-\mathrm{KCl}-\mathrm{DyCl}_{3}(1.34 \times$ $10^{-4} \mathrm{~mol} \mathrm{~cm}^{-3}$ ) salts. The thickness of the $\mathrm{Cu}$-Dy alloy layer was about $50 \mu \mathrm{m}$. The EDS point analysis labeled A shown in Fig. 12a shows that the $\mathrm{Cu} / \mathrm{Dy}$ atomic ratio approaches 4.5 . The JADE 5.0 software does not provide enough data for parsing the XRD source data obtained from the Cu-Dy sample. However, according to the results of the EDS analysis, we suggested that the deposit layer may consist of the $\mathrm{Cu}_{9 / 2}$ Dy compound
(Fig. 11d). Combined with the XRD result (Fig. 9b), we infer that the alloy layer consists of the $\mathrm{Cu}_{2}$ Dy intermetallic compound.

Fig. 13 shows the SEM-EDS of the $\mathrm{Cu}$-Dy alloy produced by potentiostatic electrolysis at $-1.55 \mathrm{~V}$ for $7 \mathrm{~h}$ on the $\mathrm{Cu}$ electrode at $773 \mathrm{~K}$. As can be seen from Fig. 13a-c, the thickness of the $\mathrm{Cu}$-Dy alloy layer is about $40 \mu \mathrm{m}$. The EDS point analysis labeled zone $\mathrm{A}$ reveals that the $\mathrm{Cu} / \mathrm{Dy}$ atomic ratio is approaching 5.6.

It can be seen from Fig. 10-13, there was an excellent binding force between the $\mathrm{Cu}-\mathrm{Dy}$ alloy layer and the $\mathrm{Cu}$ matrix. Under the same electrolysis conditions, the applied potential can affect the formation of the $\mathrm{Cu}$-Dy compound and the thickness of alloy layer.

Furthermore, the change of the Dy(III) concentration was monitored by ICP-AES during potentiostatic electrolysis at $-2.15 \mathrm{~V}$ in LiCl-KCl molten salts at $773 \mathrm{~K}$. According to eqn (12), the extraction efficiencies of Dy were evaluated during various electrolysis times.

$$
\eta=\left(C_{\mathrm{i}}-C_{\mathrm{f}}\right) / C_{\mathrm{i}} \times 100 \%
$$

where $C_{\mathrm{i}}$ and $C_{\mathrm{f}}$ are the initial and final concentrations of Dy(III) ions in the melts, respectively.

Table 5 list the change of Dy(III) concentrations in the molten salts and extraction efficiencies $(\eta)$ of Dy metal during the extraction process. As can be seen from Table 5 , the
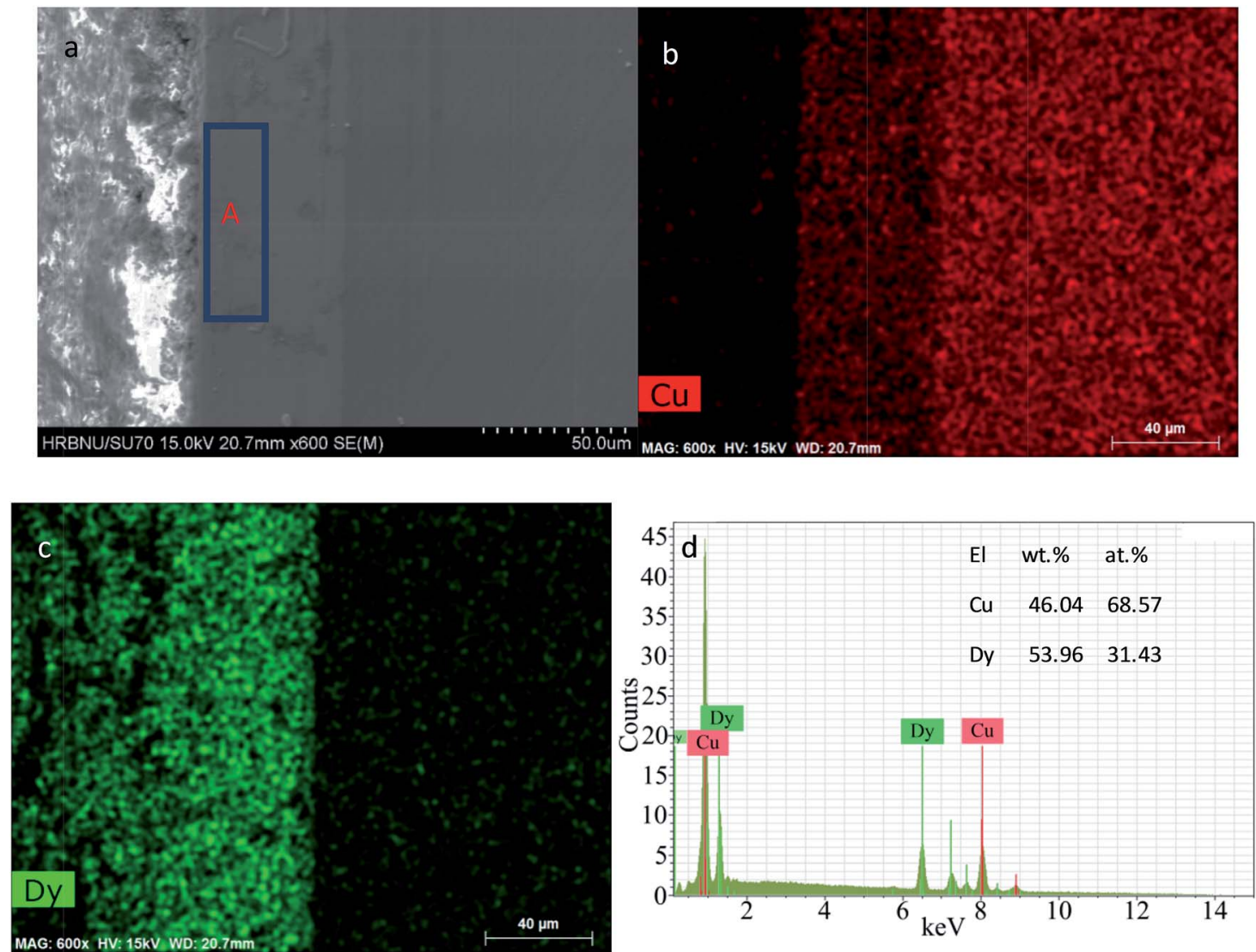

Fig. $11 \mathrm{SEM}$-EDS of deposit obtained by potentiostatic electrolysis at $-1.77 \mathrm{~V}$ on the $\mathrm{Cu}\left(\mathrm{S}=2.15 \mathrm{~cm}^{2}\right)$ electrode in molten $\mathrm{LiCl}-\mathrm{KCl}-\mathrm{DyCl}$ salts for $7 \mathrm{~h}$ at 773 K. (a) SEM; (b) and (c) EDS mapping analysis; (d) EDS point analysis of zone A in (a). 

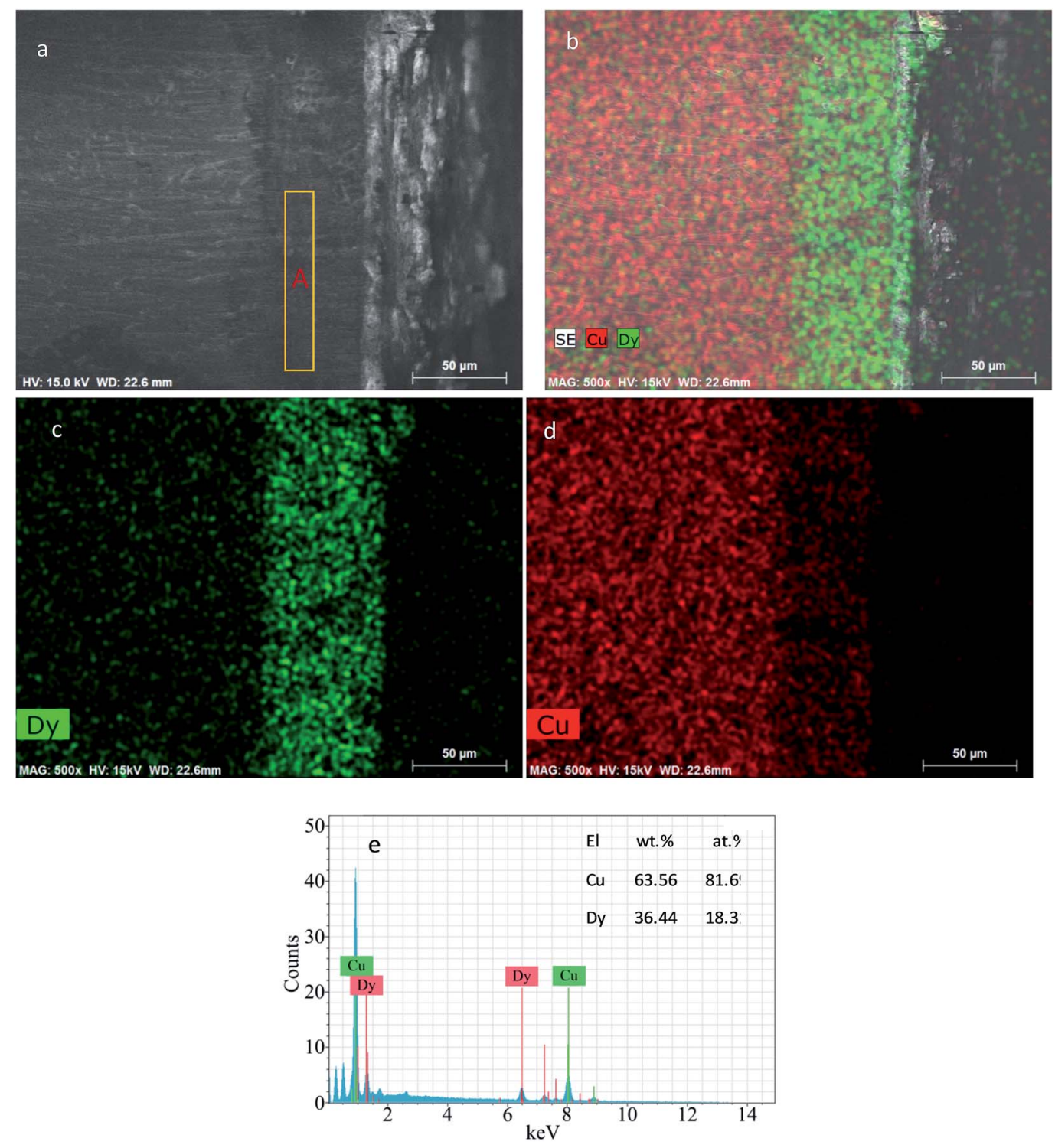

Fig. $12 \mathrm{SEM}$-EDS of deposit obtained by potentiostatic electrolysis at $-1.7 \mathrm{~V}$ on the $\mathrm{Cu}\left(\mathrm{S}=2.15 \mathrm{~cm}^{2}\right)$ electrode in $\mathrm{LiCl}-\mathrm{KCl}-\mathrm{DyCl} 3 \mathrm{melts}$ for $7 \mathrm{~h}$ at 773 K. (a) SEM; (b)-(d) EDS mapping analyses; (e) EDS point analysis of point A.
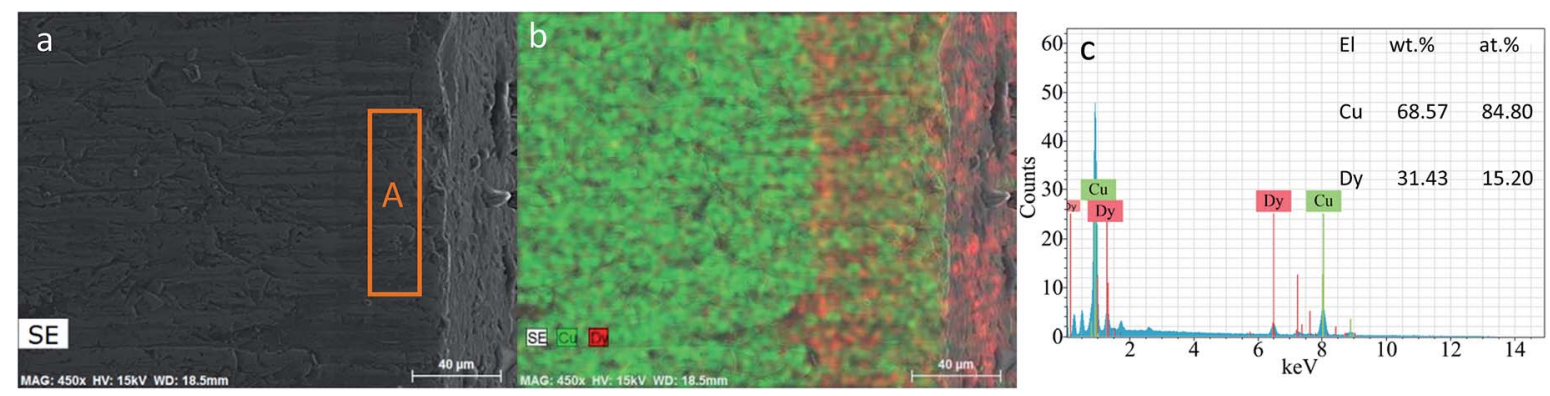

Fig. $13 \mathrm{SEM}$-EDS of deposit obtained by potentiostatic electrolysis at $-1.55 \mathrm{~V}$ on the $\mathrm{Cu}\left(\mathrm{S}=2.15 \mathrm{~cm}^{2}\right)$ electrode in molten $\mathrm{LiCl}-\mathrm{KCl}-\mathrm{DyCl} 3$ salts for $7 \mathrm{~h}$ at $773 \mathrm{~K}$. (a) SEM; (b) EDS mapping analysis; (c) EDS zoned analysis of point A shown in (a).

concentration of Dy(III) in the molten salt decreased from $1.34 \times$ $10^{-4} \mathrm{~mol} \mathrm{~cm}{ }^{-3}$ to $1.04 \times 10^{-6} \mathrm{~mol} \mathrm{~cm}{ }^{-3}$. The extraction efficiency of Dy increases with prolonging electrolysis time. The maximum extraction efficiency can reach $99.2 \%$ after electrochemical extraction for $16 \mathrm{~h}$. The extraction efficiency of Dy on the $\mathrm{Mg}$ electrode from $\mathrm{LiCl}-\mathrm{KCl}-\mathrm{DyCl}_{3}\left(6.2 \times 10^{-5} \mathrm{~mol} \mathrm{~cm}^{-3}\right)$ 
Table 5 The extraction efficiency of dysprosium was calculated using different methods

\begin{tabular}{|c|c|c|c|c|}
\hline \multirow[b]{2}{*}{$\begin{array}{l}\text { Extraction time } \\
\mathrm{h}^{-1}\end{array}$} & \multirow[b]{2}{*}{$\begin{array}{l}\text { Concentration of } \\
\text { Dy }\left(\text { (III) } \times 10^{-4} / \mathrm{mol} \mathrm{cm}^{-3}\right.\end{array}$} & \multirow[b]{2}{*}{$\begin{array}{l}\text { Mass of Dy on } \\
\text { the } \mathrm{Cu} \text { electrode/g }\end{array}$} & \multicolumn{2}{|c|}{ Extraction efficiency/\% } \\
\hline & & & ICP-AES & $\begin{array}{l}\text { Mass of Dy on } \\
\text { the Cu electrode }\end{array}$ \\
\hline 0 & 1.340 & 0 & 0 & 0 \\
\hline 3 & 0.805 & 0.4218 & 39.9 & 38.7 \\
\hline 8 & 0.114 & 0.9341 & 91.5 & 85.8 \\
\hline 12 & 0.013 & 1.0134 & 99.0 & 93.1 \\
\hline 16 & 0.011 & 1.0139 & 99.2 & 93.1 \\
\hline
\end{tabular}

melts was calculated to be $98.4 \%$ by potentiostatic electrolysis for $24 \mathrm{~h}$ at $773 \mathrm{~K} .{ }^{13}$ Compared with the extraction efficiency of Dy on the $\mathrm{Mg}$ electrode, the extraction of Dy on $\mathrm{Cu}$ electrode from LiCl-KCl-DyCl ${ }_{3}$ molten salt is more efficient.

Meanwhile, the increment of $\mathrm{Cu}$ electrode was recorded at a different electrolysis time. According to the mass change of the $\mathrm{Cu}$ electrode, the extraction quality of the Dy metal was obtained and the extraction efficiency of Dy was also calculated and presented in Table 5 . It can be seen from Table 5, there are differences between the extraction efficiencies calculated by the mass change of the working electrode and by ICP-AES. The reason may be that the deposits on the working electrode is physically detached due to harsh condition of electrolysis or large size of the deposit itself, this detached deposit may fall into the molten salts in the form of residue, which reduces the mass of the extraction product. The experimental results indicate that it is effective to extract Dy using $\mathrm{Cu}$ as the cathode by potentiostatic electrolysis in molten chlorides.

\section{Conclusion}

The electrochemical behavior of Dy(III) was first studied on $\mathrm{W}$ in eutectic LiCl-KCl using the electrochemical technique. CV and current reversal chronopotentiogram revealed that the electrochemical reduction of Dy(III) to Dy(0) proceeded in a one-step process involving three electrons. Then, the electrochemical study of Dy(III) on the Cu electrode was carried out in eutectic LiCl-KCl by CV, SWV and OCP. The results of CV and SWV showed that five typical signals correspond to the formation of different $\mathrm{Cu}$-Dy intermetallics. In addition, the standard molar Gibbs free energies, enthalpies, entropies and equilibrium constants of formation for $\mathrm{Cu}_{5} \mathrm{Dy}, \mathrm{Cu}_{9 / 2} \mathrm{Dy}, \mathrm{Cu}_{2}$ Dy and $\mathrm{CuDy}$ intermetallics were evaluated by emf measurements in the temperature range of $773-863 \mathrm{~K}$. The $j_{0}$ for $\mathrm{Dy}(\mathrm{III}) / \mathrm{Cu}_{5} \mathrm{Dy}$ and Dy(III) $/ \mathrm{Cu}_{9 / 2}$ Dy couples were determined by LP. The variation of $j_{0}$ with temperature was found to follow the Arrhenius law, from which the activation energies for $\mathrm{Dy}(\mathrm{III}) / \mathrm{Cu}_{5} \mathrm{Dy}$ and $\mathrm{Dy}(\mathrm{III}) /$ $\mathrm{Cu}_{9 / 2}$ Dy couples were determined and found to be $26.08 \mathrm{~kJ} \mathrm{~mol}^{-1}$ and $22.55 \mathrm{~kJ} \mathrm{~mol}^{-1}$, respectively. Electrochemical extraction of Dy was performed on the $\mathrm{Cu}$ electrode in molten $\mathrm{LiCl}-\mathrm{KCl}-\mathrm{DyCl}_{3}$ salts at different potentials, and five $\mathrm{Cu}$-Dy compounds, $\mathrm{Cu}_{0.99} \mathrm{Dy}_{0.01}, \mathrm{Cu}_{5} \mathrm{Dy}, \mathrm{Cu}_{9 / 2} \mathrm{Dy}, \mathrm{Cu}_{2}$ Dy and CuDy, were analyzed by XRD and SEM-EDS. The results indicated that applied potential could affect the formation of the $\mathrm{Cu}$-Dy intermetallic compound, and the metastable phase could easily form in molten chlorides on the $\mathrm{Cu}$ electrode. The change of the Dy(III) concentration was monitored by ICP-AES during electroextraction at different times and extraction efficiency was calculated. After $16 \mathrm{~h}$ electrolysis, the maximum extraction efficiency could reach $99.2 \%$, which indicated that electrochemical extracting Dy on the $\mathrm{Cu}$ electrode is feasible from molten chloride.

\section{Conflicts of interest}

There are no conflicts to declare.

\section{Acknowledgements}

The work was financially supported by the National Natural Science Foundation of China (11575047, 11675044, 21790373, 21271054 and 21173060), the Major Research Plan of the National Natural Science Foundation of China (91326113 and 91226201), National Natural Science Foundation of China (U1630102) and the Fundamental Research Funds for the Central Universities (HEUCFP201790).

\section{References}

1 T. Koyama, M. Iizuka, Y. Shoji, R. Fujita, H. Tanaka, T. Kobayashi and M. Tokiwai, J. Nucl. Sci. Technol., 1997, 34, 384-393.

2 T. H. Pigford, CA, UCB-NE-4176, Rev. 1, Department of Nuclear Engineering. University of California at Berkeley, 1990.

3 M. Iizuka, K. Uozumi, T. Inoue, T. Iwai, O. Shirai and Y. Arai, 6th Information Exchange Meeting on Actinide and Fission Product P\&T, Madrid, 2000.

4 J. Uhlír and M. Mareček, J. Fluorine Chem., 2009, 130, 89-93.

5 K. Kinoshita, T. Koyama, T. Inoue, M. Ougier and J. P. Glatz, J. Phys. Chem. Solids, 2005, 66, 619-624.

6 G. Y. Kim, D. Yoon, S. Paek, S. H. Kim, T. J. Kim and D. H. Ahn, J. Electroanal. Chem., 2012, 682, 128-135.

7 O. Conocar, N. Douyere and J. Lacquement, J. Nucl. Mater., 2005, 344, 136-141.

8 M. Iizuka, T. Koyama, N. Kondo, R. Fujita and H. Tanaka, J. Nucl. Mater., 1997, 247, 183-190.

9 Y. Castrillejo, A. Vega, M. Vega, P. Hernández, J. A. Rodriguez and E. Barrado, Electrochim. Acta, 2014, 118, 58-66. 
10 M. R. Bermejo, E. Barrado, A. M. Martínez and Y. Castrillejo, J. Electroanal. Chem., 2008, 617, 85-100.

11 M. Li, Q. Q. Gu, W. Han, Y. D. Yan, M. L. Zhang, Y. Sun and W. Q. Shi, Electrochim. Acta, 2015, 167, 139-146.

12 Y. C. Wang, M. Li, W. Han, M. L. Zhang, Y. S. Yang, Y. Sun, Y. C. Zhao and Y. D. Yan, J. Solid State Electrochem., 2015, 19, 3629-3638.

13 Y. S. Yang, M. L. Zhang, W. Han, P. Y. Sun, B. Liu, H. L. Jiang, T. Jiang, S. M. Peng, M. Li, K. Ye and Y. D. Yan, Electrochim. Acta, 2014, 118, 150-156.

14 X. Li, Y. D. Yan, M. L. Zhang, H. Tang, D. B. Ji, W. Han, Y. Xue and Z. J. Zhang, Electrochim. Acta, 2014, 135, 327-335.

15 T. Iida, T. Nohira and Y. Ito, Electrochim. Acta, 2003, 48, 1531-1536.

16 T. Nohira, H. Kambara, K. Amezawa and Y. Ito, J. Electrochem. Soc., 2005, 152, C183-C189.

17 M. Li, T. T. Sun, Y. Sun, W. Han and M. L. Zhang, Acta Phys. Chim. Sin., 2015, 31, 309-314.

18 P. Chamelot, L. Massot, C. Hamel, C. Nourry and P. Taxil, J. Nucl. Mater., 2007, 360, 64-74.

19 H. Konishi, T. Nohira and Y. Ito, Electrochem. Solid-State Lett., 2002, 5, B37-B39.

20 S. Kobayashi, T. Nohira, K. Kobayashi, K. Yasuda, R. Hagiwara, T. Oishi and H. Konishi, J. Electrochem. Soc., 2012, 159, E193-E197.

21 W. Han, Q. N. Sheng, M. L. Zhang, M. Li, T. T. Sun, Y. C. Liu, K. Ye, Y. D. Yan and Y. C. Wang, Metall. Mater. Trans. B, 2013, 45, 929-935.

22 M. Li, W. Li, W. Han, M. L. Zhang and Y. D. Yan, Chem. J. Chin. Univ., 2014, 35, 2662-2667.

23 M. Li, T. T. Sun, W. Han, S. S. Wang, M. L. Zhang and Y. D. Yan, Chin. J. Inorg. Chem., 2015, 31, 177-182.

24 P. Taxil, L. Massot, C. Nourry, M. Gibilaro, P. Chamelot and L. Cassayre, J. Fluorine Chem., 2009, 130, 94-101.

25 A. Saïla, M. Gibilaro, L. Massot, P. Chamelot, P. Taxil and A. M. Affoune, J. Electroanal. Chem., 2010, 642, 150-156.

26 C. Nourry, L. Massot, P. Chamelot and P. Taxil, J. Appl. Electrochem., 2008, 39, 927-933.
27 M. Gibilaro, L. Massot, P. Chamelot, L. Cassayre and P. Taxil, Electrochim. Acta, 2009, 55, 281-287.

28 M. Li, B. Liu, N. Ji, Y. Sun, W. Han, T. Jiang, S. M. Peng, Y. D. Yan and M. L. Zhang, Electrochim. Acta, 2016, 193, 54-62.

29 Y. Wang, M. Li, W. Han, M. L. Zhang, T. Jiang, S. M. Peng and Y. D. Yan, J. Alloy. Comp., 2017, 695, 3484-3494.

30 Y. Castrillejo, M. R. Bermejo, A. I. Barrado, R. Pardo, E. Barrado and A. M. Martínez, Electrochim. Acta, 2005, 50, 2047-2057.

31 H. Konishi, T. Nohira and Y. Ito, Electrochim. Acta, 2002, 47, 3533-3539.

32 K. Sato, Y. Yosida, Y. Isikawa and K. Mori, J. Magn. Magn. Mater., 1986, 54, 467-468.

33 S. K. Tripathy, K. G. Suresh, R. Nirmala, A. K. Nigam and S. K. Malik, Solid State Commun., 2005, 134, 323-327.

34 H. Konishi, T. Nohira and Y. Ito, J. Electrochem. Soc., 2001, 148, C506-C511.

35 K. Yasuda, S. Kobayashi, T. Nohira and R. Hagiwara, Electrochim. Acta, 2013, 106, 293-300.

36 K. H. Muller, B. Idzikowski, D. Eckert, K. Nenkov, H. J. Engelmann, A. Teresiak and M. Wolf, IEEE Trans. Magn., 1997, 33, 3565-3567.

37 Z. Wang, J. Ju, J. Wang, W. Yin, R. Chen, M. Li, C. Jin, X. Tang, D. Lee and A. Yan, Sci. Rep., 2016, 6, 38335.

38 K. Sridharan, S. Martin, M. Mohammadian, J. Sager, T. Allen and M. Simpson, Trans. Am. Nucl. Soc., 2012, 106, 1240-1241.

39 L. L. Su, K. Liu, Y. L. Liu, L. Wang, L. Y. Yuan, L. Wang, Z. J. Li, X. L. Zhao, Z. F. Chai and W. Q. Shi, Electrochim. Acta, 2014, 147, 87-95.

40 H. Okamoto, J. Phase Equilibria Diffusion, 2013, 35, 195-207.

41 M. Palumbo, L. Battezzati, A. Pasturel, S. G. Schönmeyer and W. Assmus, Calphad, 2009, 33, 511-516.

42 Y. Castrillejo, C. Abejbn, M. Vega and R. Pardo, Electrochim. Acta, 1997, 42, 1495-1506.

43 F. Sommer, J. Schott and B. Predel, J. Less Common Met., 1986, 125, 175-181.

44 A. J. Bard and L. R. Faulkner, Electrochemical Methods, Fundamental and Applications, Wiley, New York, 2001, p. 308. 